\title{
Inovação no paradigma curricular: os Projetos Temáticos em Geologia
}

\author{
Rualdo Menegat \\ Instituto de Geociências, Universidade \\ Federal do Rio Grande do Sul. \\ rualdo.menegat@ufrgs.br \\ Ana Maria Pimentel Mizusaki \\ Instituto de Geociências, Universidade \\ Federal do Rio Grande do Sul. \\ Marcus Remus \\ Instituto de Geociências, Universidade \\ Federal do Rio Grande do Sul. \\ Lidia Maria Vignol Lelarge \\ Instituto de Geociências, Universidade \\ Federal do Rio Grande do Sul. \\ Norberto Dani \\ Instituto de Geociências, Universidade \\ Federal do Rio Grande do Sul.
}

\begin{abstract}
InNovation in a CuRriculum paradigm: the Thematic Projects in Geology. For about 40 years the geology course at UFRGS formed professionals based on an unchanging curriculum and a graduate work throughout a basic geological mapping. From the 1990s has begun a thorough curriculum change that culminated in early 2000 with the implementation of a new type of graduate work or thesis, called Thematic Projects in Geology. The purpose of this article is to discuss the historical context of the paradigm shift in geology training after a long period of dictatorial government in Brazil. Moreover, it exposes the mode of operation and characteristics of the Thematic Projects and major achievements in 13 years of its development in a democratic and public university. Finally, set up some thoughts on the possible advances in quality career training in complex technical and democratic scientific contexts. Citation: Menegat R. 2014. Projetos Temáticos como Trabalhos de Conclusão de Curso de Geologia. Terræ Didatica, 10(3):204-216. http://www.ige.unicamp.br/terraedidatica/.
\end{abstract}

KEYWORDS: Curriculum change, vocational training, curriculum, graduate thesis, academic quality.

RESUMO Durante cerca de 40 anos o curso de geologia da UFRGS formou profissionais com base em um currículo cujo trabalho de conclusão dava-se por meio de um mapeamento geológico básico. A partir dos anos de 1990, deu-se início a uma profunda mudança curricular que culminou, no início dos anos 2000, com a implantação de nova modalidade de trabalho de conclusão do curso, denominada de Projetos Temáticos em Geologia. O propósito do presente artigo é discutir o contexto histórico da mudança de paradigma na formação profissional depois de um longo período de autoritarismo institucional que foi vigente durante o regime militar. Além disso, expõe-se o modo de funcionamento e as características dos Projetos Temáticos e os principais resultados alcançados em 13 anos de desenvolvimento em uma instituição universitária pública e democrática. Por fim, estabelecem-se algumas reflexões sobre os avanços possíveis na formação profissional de qualidade em contextos técnico-científicos complexos e democráticos.

PALAVRAS-CHAVES: Mudança curricular, formação profissional, estrutura curricular, trabalho de conclusão de curso, qualidade acadêmica. 


\section{Introdução}

O curso de geologia da UFRGS foi implantado em 1957, no governo democrático de Juscelino Kubitschek de Oliveira. Desde sua criação até o ano de 1994, o curso não passou por nenhuma grande reforma de seu paradigma curricular e foi apenas a partir no ano 2000 que adotou uma modalidade de trabalho de conclusão do curso diferente do mapeamento geológico básico. Durante esse tempo, foram realizadas 43 edições de mapeamento geológico, caracterizando um paradigma de formação profissional em geologia no Brasil. Inicia-se este artigo analisando o contexto histórico da formação profissional por meio dessa modalidade exclusiva de mapeamento geológico. Aqui, procuramos evidenciar as diversas fases conjunturais que se sucederem na formação de geólogos até o momento da mudança curricular em que se adotaram os projetos temáticos em geologia (PTGeo) como nova atividade de trabalho de conclusão do curso. Longe de esgotar a análise histórica, tecemos um breve apanhado em que se torna evidente o longo período de instalação do curso e construção de um paradigma de formação do geólogo que vai de 1957 a 1980. Grande parte do período ocorreu sob uma atmosfera de autoritarismo dentro das universidades durante o regime militar que contrasta com a crise do mercado profissional que se abre nos anos de 1980 juntamente com a derrocada do regime militar e a redemocratização do país. Embora esse novo momento conjuntural tenha se dado desde 1984, as mudanças curriculares somente iniciaram a partir de 1992, manifestando a inércia institucional das universidades vivida em função do antigo regime. Por fim, comentamos o último período em que se tornou possível a mudança de paradigma na formação de geólogos a partir de 1992 e, mais destacadamente, do ano 2000.

$\mathrm{Na}$ segunda parte desse artigo, apresentamos a nova estrutura curricular e o modo de funcionamento dos projetos temáticos em geologia implantados a partir do ano 2000. Detalha-se a maneira como os alunos elaboram os projetos que contam com dois orientadores e como são desenvolvidos por meio de três disciplinas, denominadas de Projeto Temático em Geologia I, II e III oferecidas respectivamente nas etapas 8,9 e 10 . Detalha-se, também, a produção da monografia final que é submetida a uma banca de avaliação. Todos os autores deste artigo coordenaram as disciplinas de Projeto Temático durante as treze primeiras edições do programa, de sorte que procuramos trazer aqui também a experiência de implantação e ulterior desenvolvimento dessa modalidade de trabalho de conclusão de curso. Além disso, analisamos em termos quantitativos as 330 monografias aprovadas nessas primeiras edições. Procurou-se reconhecer as principais concentrações temáticas dos trabalhos apresentados, enunciadas em termos de seis grandes grupos denominados de itinerários formativos, e subtemáticas, onde foram identificadas 19 modalidades $\mathrm{O}$ objetivo do levantamento minucioso desses dados foi o de dar suporte à tese de que o programa trouxe grande inovação na formação profissional em relação ao paradigma clássico. Para levar a frente a classificação temática dos trabalhos, utilizaram-se os registros constantes no sistema da biblioteca do Instituto de Geociências, em vez das anotações das disciplinas. Isso porque os trabalhos estão disponibilizados pelo sistema de informatização documental da biblioteca do Instituto de Geociências. O artigo é finalizado com uma reflexão sobre a importância dos projetos temáticos para propiciar um contexto de inovação e qualidade na formação de geólogos.

\section{A construção de um paradigma de formação de geólogos no Brasil}

\section{Acerca de uma época heroica do período fundacional}

Até a década de 1950, não havia cursos específicos para a formação de geólogos no Brasil, razão pela qual houve uma campanha nacional para que isso viesse a ocorrer. A campanha ficou conhecida como CAGE (Campanha de Formação de Geólogos), tendo sido liderada, entre outros, pelo professor Irajá Damiani Pinto, um dos mais importantes paleontólogos do Brasil (Pinto 2007, Menegat e Araújo 2005). A CAGE levou à implantação do curso de Geologia da UFRGS, juntamente com aqueles da USP, UFOP e UFPE. O curso sul-rio-grandense obteve reconhecimento em 18 de janeiro de 1957 por meio do Decreto número 40783/57, e a primeira turma de geólogos formou-se no ano de 1960, quando o curso tinha a duração de quatro anos.

O período inicial de implantação do curso de Geologia pode ser considerado como "heroico", pois foi preciso de certa forma inventar um modo de formar geólogos no Brasil. Não havia muitos 
professores brasileiros para assumir a docência em geologia e, por isso, boa parte dela foi constituída por profissionais provenientes dos Estados Unidos da América e também de outras áreas de conhecimento, como engenharias, em especial a engenharia de minas, a química e a história natural (Pinto 2007). A estratégia geral do curso coadunava-se com o esforço nacional de realizar mapeamentos geológicos básicos. Assim, nessa época e durante um longo período, o trabalho de conclusão do curso, chamado de "Trabalho de Graduação (TG)", tinha a finalidade de treinar os alunos nas técnicas de mapeamento geológico e produzir mapas geológicos. A logística dos trabalhos de campo era bastante rústica, a qual se utilizava de acampamentos que envolviam toda a comunidade na sua organização: funcionários cuidavam da alimentação e das conduções, alunos e professores montavam barracas, improvisavam laboratórios e tratavam da coleta de dados. O espírito de grupo proporcionou grande coesão da comunidade geológica e foi o esteio para a construção do mito do geólogo: 'desbravador e voluntarioso'.

A estratégia de mapeamento foi vigente desde o início da fundação da Escola, em 1957, até o ano 2000. Ao todo, foram realizadas 41 edições de mapeamentos geológicos por meio dos Trabalhos de Conclusão do Curso, ou "TG's (Trabalhos de Graduação)", que, integrados com trabalhos de campo levantados em outras instituições, possibilitaram a publicação de mapas regionais editados pela escola de geologia. A partir do final dos anos de 1980, a Companhia de Pesquisa de Recursos Minerais (CPRM) passou a liderar a atividade.

\section{A fase de ouro nos anos de chumbo}

Nos anos 1970, as companhias de mineração e exploração de petróleo atingiram novos patamares de expansão. Por isso, parte da formação e produção do conhecimento geológico básico passou a ser feita no âmbito das próprias empresas. A Petrobras, por exemplo, passou a elaborar técnicas cada vez mais avançadas em estratigrafia e produção do petróleo. A CVRD - Companhia Vale do Rio Doce, uma ex-estatal - desenvolveu técnicas de mapeamento geológico, geologia econômica e prospecção mineral em áreas até então de difícil acesso do território nacional. Com isso, a formação básica em geologia nas universidades foi ficando aquém do desenvolvimento tecnológico que as empresas possuíam. Por outro lado, as universidades passaram a implantar e ampliar Cursos de Pós-Graduação, de modo a investir mais profissionalmente na pesquisa avançada e em técnicas analíticas para além do trabalho de mapeamento levado a efeito no curso de graduação.

Em todo esse período, a maior parte dos egressos em geologia foi contratada por grandes empresas públicas, tornando a profissão ligada ao grande investimento empresarial estatal (Assine 1994). Isso fez com que a formação nas universidades não fosse muito exigida, pois as empresas tinham seus próprios mecanismos de atualização profissional. Além disso, não eram comuns as críticas em plena Ditadura Militar, de sorte que não havia um processo claro de avaliação do curso pelas instituições de ensino.

\section{Sintomas de anacronismo começaram a aparecer nos anos 1980}

A partir dos anos 1980, a comunidade geológica passou a dar-se conta do anacronismo da formação de geólogos nas universidades brasileiras ao mesmo tempo em que a Ditadura Militar ia perdendo sua hegemonia. Nessa época, de um total de 19 cursos, apenas dois eram oferecidos em universidades particulares. A formação de geólogos no Brasil constituía-se, também, em um empreendimento quase que exclusivamente estatal (SBG 1983, Assine 1994). Em 1982, foi realizado o primeiro Seminário Nacional sobre Ensino e Currículo de Geologia, promovido pela Sociedade Brasileira de Geologia (SBGeo) e a Executiva Nacional dos Estudantes de Geologia (ENEGE). Contudo, os excelentes resultados do seminário, que apontaram para a necessidade de mudanças significativas do currículo de Geologia, acabaram ficando apenas nos relatórios ali produzidos (SBG 1983, SBG 1984).

Embora os problemas relacionados com a fragmentação do currículo tivessem sido diagnosticados, as discussões esmaeceram com o tempo e poucas mudanças foram efetivadas. Certamente, muitas das considerações daquela época ainda são válidas nos dias atuais.

Assim o professor José Raymundo de Andrade Ramos [1923-2013], da UFRJ, reportou-se em relação à crise da época:

Sonhei uma geologia bem ensinada, em currículos completos, não como aquele que eu tive, incompleto, incompreendido, autodidático, complementado em terras estrangeiras. [...] Hoje, nos cursos de geologia o anseio é um só. Anseio de tempo de crise: qualidade (Ramos 1987). 


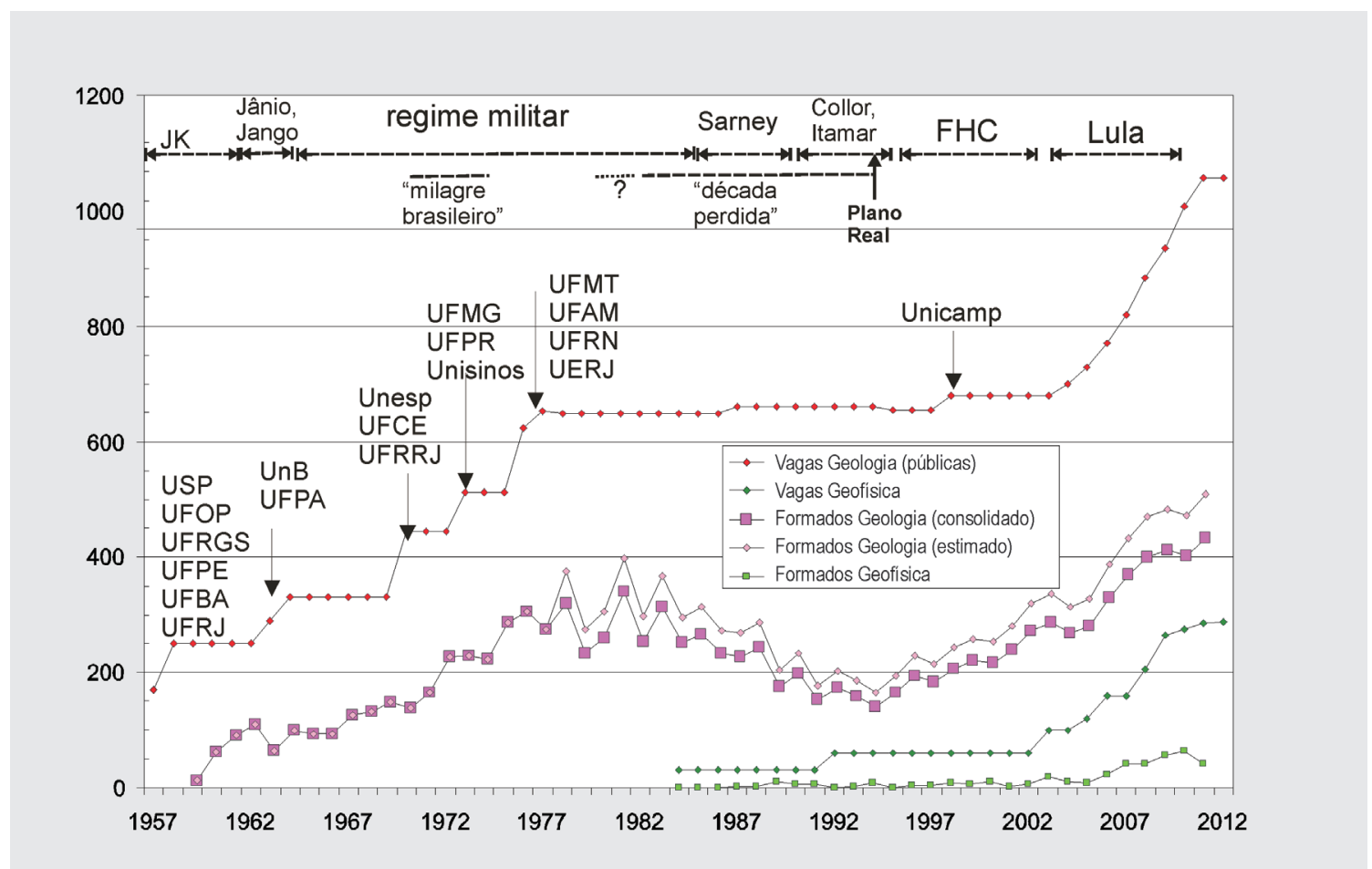

Figura 1. Número de vagas e de formados nos cursos de geologia brasileiros desde 1959 até 2012 (Fonte: Janasi 2012).

Durante a greve das universidades públicas havida em 1987, a comunidade do curso de Geologia da UFRGS tratou, pela primeira vez de forma sistemática e aberta, a necessidade de revisar seu currículo. Os resultados da discussão, contudo, tiveram pouco resultado imediato. Por um lado, ainda havia o enorme peso dos anos de chumbo sobre a universidade e, por outro, o mercado profissional na área da mineração e extração de petróleo encontrava-se em brutal retração. Isso fez aumentar os indícios de que era preciso repensar a formação dos geólogos mais além da crise e com urgência.

\section{Como mudar um paradigma curricular de 42 anos?}

O fim do paradigma clássico de formação de geólogos deu-se conjuntamente com as profundas mudanças que tiveram lugar em todo o mundo a partir de 1989, cujo marco foi a queda do muro de Berlim. A partir desse ano, empresas estatais tidas como inabaláveis foram privatizadas pelas políticas neoliberais, o Estado foi sendo reduzido e as Universidades nunca haviam sofrido uma onda tão forte de desestruturação, sucateamento e desmobilização moral. A crise na mineração intensificou-se e o mercado de geólogos sofreu um dos maiores reveses da história recente da profissão. Nos Esta- dos Unidos, que possuía cerca de 70 mil profissionais na área, surgiram projetos até para ser fechado o importante Serviço Geológico daquele país (USGS, na sigla em inglês), um dos pioneiros no mundo e referência internacional. No início dos anos 1980, formavam-se nos EUA cerca de sete mil geólogos. No final dessa década, o número decresceu para cerca de 1.800. (Keane 2010, USGS 2011) O paradigma profissional clássico da geologia calcado no trinômio 'mapeamento, mineração e petróleo' chegara ao seu fim.

Em um levantamento da quantidade de vagas e de egressos dos cursos de geologia brasileiros feito pelo professor Valdecir Janasi (Janasi 2012), pode-se ver claramente a curva depressiva dos anos de 1980 e 1990 (Fig. 1). O número de formados que era de cerca de 400 no ano de 1982 despenca para menos de 200 no ano de 1992.

Em 1992, ano de uma das mais vigorosas greves das universidades federais, a comunidade do Curso de Geologia da UFRGS aprofundou as discussões sobre currículo e formação profissional como nunca fizera até então. Foram mais de 15 reuniões gerais de professores, alunos e funcionários; além de 18 entre o corpo docente e 12 entre o corpo discente. O resultado deixou os participantes esperançosos, afinal, era possível construir uma alternativa para enfrentar as várias crises que se colocavam. 


\section{A grande mudança curricular de 1992}

As discussões realizadas traçaram novas diretrizes básicas que se embasavam: (a) na necessidade de introduzir uma formação continuada de Geologia de campo, por meio de disciplinas anuais e seriadas denominadas de "Trabalho de Campo I, II, III, e IV", de modo a exigir do alunado progressivas exigências técnicas de levantamento de dados; (b) no encadeamento epistemológico da formação em geologia, o qual partiria de disciplinais globais introdutórias no primeiro ano, sucedidas por disciplinas de instrumentação técnica no segundo e terceiro anos, e de disciplinas globais aprofundadas no quarto ano, para, no quinto ano, culminar com disciplinas profissionalizantes reunidas em termos de itinerários formativos; (c) na capacitação de um profissional capaz de elaborar e resolver problemas, de modo a enfrentar em melhores condições o mercado de trabalho que se apresentava difuso, em franca transformação e com exigências de qualificação e interdisciplinaridade crescentes; (d) na substituição da atividade de mapeamento geológico como exclusiva do Trabalho de Graduação (TG), conforme havia sido implantado no início da fundação da Escola de Geologia, por um Projeto Temático em Geologia, cuja monografia de conclusão devesse apresentar um problema, e respectivas técnicas e dados para sua solução. Os trabalhos temáticos seriam orientados por professores pertencentes a núcleos temáticos, além de terem suporte formativo a partir de três disciplinas eletivas a serem cursadas durante os dois últimos anos do curso.

Com o resultado das discussões, um novo currículo foi implantando a partir de 1994. Contudo, o currículo atendeu parcialmente ao conjunto das mudanças sugeridas. Foram alteradas as disciplinas dos quatro primeiros anos e foi ainda mantido o mapeamento geológico (os TG's) como atividade exclusiva do Trabalho de Conclusão de Curso. Isso era equivalente a dizer que foram mantidas (a) as apostas em um possível renascimento do paradigma profissional clássico da geologia e também (b) a estratégia de formação profissional formulada ainda nos anos 50, quando da criação do curso.

\section{A crise do mercado clássico do geólogo: 0 advento de novas modalidades profissionais e a autonomia universitária}

Com efeito, muitos consideraram que a crise do mercado profissional na geologia fosse passageira e que haveria uma retomada da mineração no curto prazo. Ou, ainda, que seria possível reverter as mudanças na economia do país derivadas da onda de privatizações, chamada de neoliberal.

Porém, a profundidade das mudanças econômicas que ocorreram no mundo, que passou a chamar-se "globalizado", foi e continua sendo enorme. Todas as empresas mudaram vigorosamente suas estratégias, chamadas, na época, de "reengenharia”, "rearquitetura", ou ainda, "planejamento estratégico". Tudo isso para enfrentar um mercado cada vez mais segmentado e tecnologicamente mais competitivo. Os países ditos em desenvolvimento ou emergentes sofreram reveses agudos cujas crises foram conhecidas como "crise dos tigres asiáticos (1997)", "efeito tequila” (1994 no México), "efeito samba" (1999 no Brasil), "efeito tango" ( 2001 na Argentina), e tantas outras que estamparam as páginas dos jornais no período. As economias que emergiram da fragmentação da União Soviética ficaram ou aniquiladas ou entraram em guerra. Mesmo economias vigorosas como a japonesa mostraram sinais de vulnerabilidade, bem como algumas economias europeias.

Além disso, a emergência dos problemas ambientais e do aquecimento global colocou novos problemas para a relação entre as atividades humanas e os recursos naturais. Estes eram considerados como sendo inesgotáveis e sua extração intensiva era vista como inofensiva para o funcionamento dos sistemas terrestres. Os novos paradigmas de sustentabilidade e gestão ambiental dos sistemas na escala planetária redimensionaram a perspectiva de atuação da geologia. Os serviços geológicos de todos os países reestruturaram suas finalidades para desenvolver uma interface de disponibilização de informações para a sociedade, de modo que esta pudesse ter elementos para discutir sua relação técnica e cultural com os sistemas da Terra (USGS 2011).

A mudança curricular equivalia, assim, a uma espécie de planejamento estratégico, o qual procurou desenvolver três questões: (a) qual o futuro profissional dos egressos em Geologia além das áreas clássicas, como seria a atuação em novas modalidades como geologia urbana, meio ambiente, riscos geológicos, desastres naturais, aquecimento global, etc.? (b) como o Curso de Geologia desenvolver-se-ia nos novos marcos da autonomia universitária, que abria os muros dessa instituição para outras formas de financiamento, incluindo a prestação de serviços? (c) como estruturar o ensino, a pesquisa e a extensão em uma nova época democrática? 


\section{Os anos 2000: a implantação dos projetos temáticos}

No ano 2000, foram finalmente implementadas aquelas mudanças curriculares propostas ainda em 1994, mas que vieram a ser aprovadas pela Comissão de Graduação e pelo Conselho da Unidade somente em 1999. Dessa forma, o trabalho de conclusão do curso deixou de ser feito por meio de um mapeamento geológico (o TG). Em seu lugar foram implantados os "Projetos Temáticos em Geologia", com o objetivo de propiciar formação profissionalizante que buscasse desenvolver no alunado a capacidade de: (i) identificar e resolver problemas dentro de uma perspectiva interdisciplinar nas Geociências e áreas afins; (ii) adquirir, tratar, analisar e integrar dados e ferramentas para organizar produtos técnicos de uso profissional e social; e (iii) elaborar modelos, conclusões e soluções técnicas e científicas relatados por meio de uma monografia técnica. Essa nova modalidade foi implementada por meio de três disciplinas (Projetos Temáticos em Geologia I, II e III) e os trabalhos passaram a ser orientados por professores agrupados em sete linhas temáticas: (a) Geotectônica e petrologia ígnea e metamórfica, (b) Mineralogia e tecnologia mineral, (c) Estratigrafia e petrologia de depósitos sedimentares e formações superficiais, (d) Geologia ambiental, hidrogeologia e geotécnica, (d) Recursos minerais e energéticos, (e) Geoprocessamento e sensoriamento remoto, (f) Geologia marinha e costeira. A partir de 2006, a orientação de trabalhos passou a ser aberta e os núcleos temáticos deixaram de existir.

Ao longo de 13 anos de desenvolvimento dos projetos temáticos, 330 monografias foram elaboradas, ampliando sobremaneira o leque das competências e habilidades profissionais dos egressos como nunca se havia imaginado antes. Além da diversidade de linhas temáticas, aumentaram as técnicas de levantamento de dados em campo e o uso na graduação de sofisticados procedimentos laboratoriais, como: geologia isotópica, microssonda eletrônica, microscopia eletrônica de varredura, difratometria de raios $\mathrm{X}$, sensoriamento remoto, gravimetria, entre outros. Os problemas geológicos tratados deixaram de ser apenas locais e ultrapassaram as fronteiras regionais, expandindo-se para muitos outros estados brasileiros. Diversos projetos tiveram lugar desde os longínquos estados como Pará, Bahia, e Sergipe, até os mais próximos, como Santa Catarina e Paraná. Também foram efetivados trabalhos em outros países, como na Argentina, Chile e Colômbia, e em continentes mais distantes, como na África e na Antártida.

O suporte logístico e financeiro para a realização dos projetos ampliaram as modalidades de relações institucionais. Grande parte dos trabalhos foi suportada pelo orçamento do Instituto de Geociências, que disponibilizou acesso a todos os laboratórios que administra, bem como infraestrutura de transporte e hospedagem. Outras fontes de suporte incluíram as agências de fomento de pesquisa em ciência e tecnologia (CNPq, Fapergs), editais de agências nacionais de regulação setorial (ANP), convênios com instituições públicas e privadas.

\section{Projetos temáticos e encadeamento curricular}

O currículo que vigorou durante cerca de 40 anos caracterizava-se pela fragmentação epistemológica, forte descritivismo, rejeição às teorias científicas, polaridade acentuada entre uma geologia dita 'física' e outra dita 'histórica', cerceamento a qualquer visão crítica, posto que foi desenvolvido em grande parte durante a ditadura militar. $\mathrm{O}$ objetivo geral era o de proporcionar uma formação 'polivalente', ou seja, o profissional egresso deveria ser capaz de desenvolver habilidades técnicas mais do que saber resolver problemas. O coroamento da formação dava-se por meio do mapeamento geológico, na época, feito como trabalho de conclusão do curso em grupos de dois a quatro alunos.

A reformulação curricular desenvolvida a partir de 1994 e concluída em 1999 considerou um encadeamento epistemológico que tinha por base um profundo desenvolvimento de habilidades técnicas sem perder a visão integrada sobre o sistema Terra e dos problemas geológicos. O currículo passou a ser estruturado em quatro estágios epistemológicos, nos quais se encadeia uma progressiva visão da complexidade e profundidade técnico-científica dos temas geológicos. Embora ainda considerado como sendo muito importante, o mapeamento geológico, agora visto como uma das possíveis técnicas da geologia, não constituía mais o trabalho de conclusão. Na nova modalidade de projetos temáticos, desenvolvidos individualmente, o aluno deve demonstrar capacidade de formular problemas e apresentar soluções dentro de uma estruturação técnico-científica de nível epistemológico mais alto do que aquela de um mapeamento. 
O primeiro estágio do encadeamento epistemológico reúne disciplinas básicas (matemática, física e química) e disciplinas integradoras introdutórias (geologia fundamental, paleontologia, mineralogia). Estas visam oferecer uma visão integrada e abrangente da dinâmica, componentes e materiais do Sistema Terra. Essas disciplinas foram distribuídas predominantemente na primeira e segunda etapa do curso, e algumas poucas na terceira e quarta etapa. Pelo encadeamento curricular, nenhuma disci-

plina desse estágio deve ficar pendente a partir da quinta etapa.

O segundo estágio epistemológico engloba as disciplinas específicas e de instrumentação técnica nas áreas de geologia ígnea, sedimentar e metamórfica, geomorfologia/cartografia/topografia e sensoriamento remoto, geofísica e geoquímica, e técnicas analíticas. As disciplinas desse estágio distribuem-se predominantemente na terceira, quarta e quinta etapa do curso, sendo que algumas poucas também nas etapas seis e sete.

O terceiro estágio agrupa disciplinas integradoras aprofundadas, como a estratigrafia, geotectônica, geologia histórica, geologia do Brasil e geologia econômica. Essas disciplinas dispõem-se na grade curricular das etapas seis e sete e, em menor número, na etapa oito. O encadeamento curricular estabelece que essas disciplinas não podem ser postergadas para as etapas nove e dez.

Por fim, o quarto estágio diz respeito aos itinerários formativos compostos pelos Projetos Temáticos em Geologia e um grupo de 3 a 6 disciplinas eletivas que visam a dar suporte técnico e conteudístico de um itinerário formativo. Os projetos temáticos são desenvolvidos a partir de três disciplinas (Projetos Temáticos em Geologia I, II, e III), sendo a primeira oferecida na etapa 8 e, as outras nas etapas 9 e 10 respectivamente. Os temas dos projetos e respectivas disciplinas eletivas foram agrupados em sete itinerários formativos, a saber: (a) geotectônica, petrologias, geoquímica, geol. regional; (b) estratigrafia, geologia sedimentar, paleontologia e petróleo; (c) geologia ambiental, urbana, hidrologia e geotécnica; (d) recursos minerais e carvão; (e) mineralogia e tecnologia mineral; (f) geoprocessamento e sensoriamento remoto; (g) geologia marinha e costeira. Os estágios epistemológicos e as correspondentes etapas do curso podem ser visualizados no organograma da Figura 2.

O ensino de campo é realizado por meio de quatro disciplinas encadeadas (Trabalho de Campo I, II, III e IV) oferecidas nas etapas pares, de sorte a possibilitar que anualmente os alunos realizem uma atividade de campo integradora e envolvendo os conteúdos das principais disciplinas cursadas nesse período. Elas desenvolvem conteúdos de campo progressivamente mais exigentes quanto a aspectos técnicos e relatórios. Além dessas disciplinas, o ensino de campo também é desenvolvido por meio de duas disciplinas de mapeamento geológico básico (I e II), e nos próprios projetos temáticos. A distribuição qualitativa e quantitativa de créditos e da carga horária total do curso é apresentada na Tabela 1.

\section{Princípios e modus operandidos Projetos Temáticos}

Os projetos temáticos em geologia implementados a partir do ano 2000 como trabalho de conclusão do curso possuem dois objetivos gerais: promover uma formação profissionalizante diversificada e empreendedora; e fazer com que o trabalho de conclusão esteja inserido nos problemas da vida profissional e universitária, favorecendo a 
Tabela 1. Tipologia de créditos e respectiva carga horária do curso de Geologia (Fonte: UFGRS 2012)

\begin{tabular}{|c|c|c|c|c|c|c|c|c|}
\hline \multicolumn{3}{|c|}{ Tipo de crédito } & \multicolumn{2}{|c|}{ Créditos } & \multicolumn{2}{|c|}{$\begin{array}{l}\text { Carga } \\
\text { Horária }\end{array}$} & \multicolumn{2}{|c|}{$\%$} \\
\hline \multirow{5}{*}{ 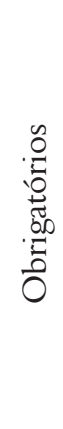 } & & Teóricos & 146 & \multirow{5}{*}{291} & 2.190 & \multirow{5}{*}{4.365} & 45 & \\
\hline & \multirow[t]{2}{*}{ Campo } & $\begin{array}{l}\text { Trabalho de Campo I, } \\
\text { II, III, IV, Mapeamento } \\
\text { Geológico I e II }\end{array}$ & 73 & & 1.095 & & 25 & \\
\hline & & $\begin{array}{c}\text { Saídas de campo de } \\
\text { disciplinas }\end{array}$ & 07 & & 105 & & 02 & 93 \\
\hline & \multicolumn{2}{|c|}{ Laboratórios/práticas } & 50 & & 750 & & 16 & \\
\hline & \multicolumn{2}{|c|}{ Projetos Temáticos I, II^, III } & 15 & & 225 & & 5 & \\
\hline \multicolumn{3}{|c|}{ Eletivos } & \multicolumn{2}{|c|}{16} & \multicolumn{2}{|c|}{240} & & 5 \\
\hline \multicolumn{3}{|c|}{ Complementares } & \multicolumn{2}{|c|}{06} & \multicolumn{2}{|c|}{90} & & 2 \\
\hline \multicolumn{3}{|c|}{ TOTAL } & \multicolumn{2}{|c|}{313} & \multicolumn{2}{|c|}{4.695} & \multicolumn{2}{|c|}{100} \\
\hline
\end{tabular}

(^) Quatro créditos da disciplina de Projeto Temático em Geologia II são relativos a trabalho de campo, os quais não foram adicionados em 'créditos obrigatórios de campo'.

integração do ensino, da pesquisa e da extensão.

O Projeto Pedagógico do Curso, aprovado por unanimidade em todas as instâncias após ampla discussão na comunidade no ano de 2011, afirma que os Projetos Temáticos são um método importante para ajudar o estudante a pensar por si mesmo. Além disso, o desenvolvimento de projetos por meio de parcerias institucionais confere maior visibilidade à ação da universidade pública, principalmente quando os projetos objetivam a elaboração continuada de diagnósticos do meio físico de abrangência regional e que, por isso, facilitam o uso dos saberes a serem adquiridos, renovando os vínculos entre Universidade pública e a sociedade.

Em termos de incentivo à inovação, a proposição de projetos aumenta a diversidade de aplicação de técnicas e métodos geológicos e, por conseguinte, da atuação profissional, por meio de consistente treinamento nos mais diversos campos inclusive aqueles que se colocam como sendo inovadores. A diversidade e inovação por meio do desenvolvimento de projetos, e não uma simples formação polivalente sem foco definido, contribui para a inserção profissional em um mercado em constante mutação. Por isso, os projetos conferem não só a necessária visibilidade do uso de técnicas na solução de problemas, mas também indica como estas como se colocam em seu uso continuado na perspectiva do mercado, e não apenas do desenvolvimento científico em si mesmo. Dessa maneira, os projetos temáticos permitem uma síntese entre ensino, pesquisa e extensão.
Mais além, os projetos inserem na formação do educando a problemática de desenvolvimento projetual em que os parâmetros institucionais e logísticos devem ser adequados caso a caso. Ou seja, o aluno-proponente é protagonista dentro da instituição ao realizar seu projeto e, ao mesmo tempo, a instituição abriga os anseios de avanço intelectual e científico dos jovens aprendizes. Isso traz um aspecto de inovação na formação no ensino da geologia no Brasil, pois a instituição dá amparo aos projetos e perspectivas pedagógicas elaboradas pelo próprio aluno. Reconhece-se no aluno uma capacidade de também formular sua perspectiva de aprendizado de acordo com as disponibilidades tecnológicas e científicas da instituição em que estuda. Isso equivale dizer que todo aparato técnico científico da instituição e aqueles que por ventura se possa arranjar por meio de parceiras está disponível institucionalmente ao aluno, sem qualquer favor. Nesse procedimento, desenvolve-se e incentiva-se o empreendedorismo que, com o paradigma antigo, não se colocava de forma plena, pois o aluno apenas somava na consecução de um projeto de mapeamento, mais do que protagonizava novas perspectivas de atuação profissional.

A elaboração, proposição e desenvolvimento de um projeto técnico científico conferem a seu autor e uma formação integral, desde os aspectos técnico-conteudísticos, até aqueles relacionados com o protagonismo autoral, que envolvem a expressão oral e escrita, a elaboração de técnicas e produtos e a defesa de seus resultados perante seus colegas e 
bancas qualificadas. O desenvolvimento do espírito crítico e da visão ética do trabalho técnico e profissional, tão necessários para a formação de alto nível de formação, encontram nessa modalidade de trabalho um amplo espectro de desenvolvimento, posto que todo o processo dá-se necessariamente de acordo com os princípios da motivação do autor, da capacidade de empreender e aprender em um contexto de uma sociedade de conhecimento.

Os projetos se orientam por itinerários temáticos formativos, que são uma espécie de célula motora da formação profissional com base em uma identidade de técnicas e métodos para a geração de tecnologias de solução de problemas. Os itinerários colocam-se como alternativa à definição de "áreas de conhecimento" que ensejam limites definidos os quais eventualmente não devem ser ultrapassados para que não seja danificada a identidade circunscrita ao limite. Ao contrário, os itinerários formativos permitem que, a partir de certa identidade de técnicas e conteúdos, possa haver a solução de problemas em zonas avançadas de interface, permitindo que o aluno trabalhe em zonas de fronteira do conhecimento e das técnicas. A formação técnica e o curso não se colocam, assim, como limites do crescimento formativo do estudante. Mais avante, o curso serve como uma base e incentiva o aluno a avançar e buscar altos níveis de qualificação já na graduação. Os itinerários preconizados pelo Projeto Pedagógico do Curso são: (a) Geotectônica e petrologia ígnea e metamórfica; (b) Mineralogia e tecnologia mineral; (c) Estratigrafia e petrologia de depósitos sedimentares e formações superficiais; (d) Geologia urbana, ambiental, hidrogeologia e geotecnia; (e) Recursos minerais e energéticos; (f) Geoprocessamento e sensoriamento remoto; (g) Geologia marinha e costeira. Cada itinerário formativo deve propor três disciplinas eletivas básicas e outras complementares para dar suporte técnico-científico ao desenvolvimento dos projetos.

\section{Da proposição de projetos e sua aprovação}

Os projetos são desenvolvidos ao longo de três disciplinas coordenadas pelo Fórum de Projetos Temáticos, o qual está subordinado à Comissão de Graduação do Curso de Geologia (Comgrad/Geo), conforme indica o organograma da Figura 3. A disciplina de Projeto Temático em Geologia I (PTGeo I) é oferecida na oitava etapa, e as disciplinas de PTGeo II e III, nas etapas nona e décima, respectivamente. De acordo com as normas da Comgrad,

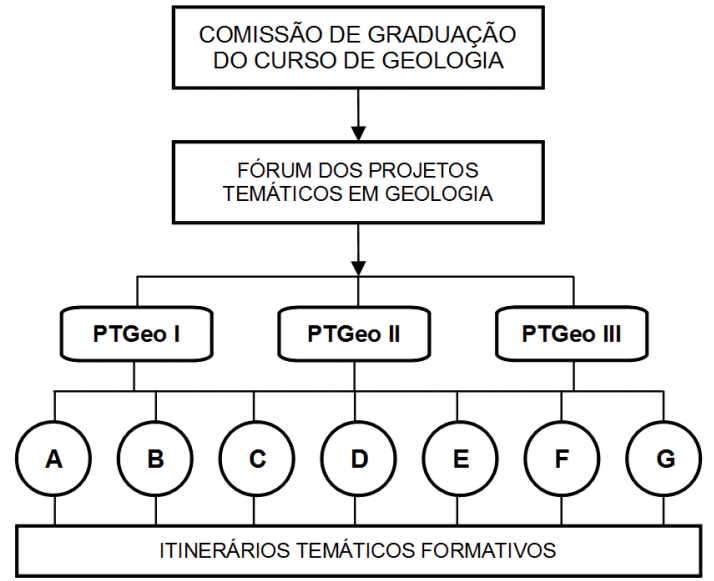

Figura 3. Organograma da estrutura dos projetos temáticos em geologia.

o Fórum dos Projetos Temáticos tem claras funções de avaliar os programas dos itinerários formativos; aprovar os cronogramas de desenvolvimento dos projetos; harmonizar o planejamento das interfaces institucionais; aprovar bancas de avaliação das disciplinas de Projetos Temáticos I, II e III; promover a avaliação e edição dos resultados.

As três disciplinas coordenam as principais funções de produção do trabalho sumarizadas em três estágios: (a) de submissão do projeto, realizada na disciplina de PTGeo I; (b) de desenvolvimento do trabalho e obtenção de dados no campo e em laboratório realizada na disciplina de PTGeo II; (c) da síntese dos resultados, finalização da redação de uma monografia e defesa por meio de uma banca, realizada na disciplina de PTGeo II. Em cada estágio o aluno apresenta oralmente seu trabalho e também por escrito, de sorte que a monografia final vai sendo construída de forma progressiva. A seguir os três estágios são descritos, para detalhar os procedimentos principais em que se estruturam.

No primeiro estágio, os projetos são elaborados durante a disciplina de Projetos Temáticos 1, e podem ter até dois professores orientadores, sendo um deles necessariamente docente do Curso de Geologia, além de um supervisor técnico. Os professores que se dispõem a orientar trabalhos são convidados a apresentar no início da disciplina possíveis temas de desenvolvimento, de sorte a acomodar eventuais alunos que ainda estejam escolhendo o itinerário e a temática que querem adotar.

O trabalho deve estabelecer uma clara delimitação do problema e das técnicas a serem empregadas para a sua resolução. Para tanto, estão disponíveis quaisquer laboratórios do Instituto de Geociên- 
cias, os quais devem oferecer cotas para atender aos projetos temáticos. Fazer com que todos os laboratórios do Instituto de Geociências acolham demandas do ensino de graduação foi uma grande conquista institucional do período democrático, levada a efeito pela adoção dos projetos temáticos, em contraste com o período ditatorial.

Além disso, nesse estágio são estruturados os arranjos institucionais de parceria, apoio e financiamento do projeto, que podem ser provenientes de instituições e empresas do setor público ou privado ou, ainda, de projetos de pesquisa dos orientadores. Quando necessário, o próprio Instituto oferece logística de apoio e financiamento do trabalho de campo dos projetos.

Cada projeto é avaliado pelos professores da disciplina (geralmente em número de dois), que analisam os aspectos mais formais, e também por um professor que constitui o itinerário formativo ao qual o projeto se inscreve. Este professor comenta os aspectos de conteúdo, como o estado da arte do problema proposto, e metodologias a serem utilizadas.

Após a aprovação do projeto na disciplina, o mesmo é submetido à COMGRAD/GEO, a quem cabe homologar tanto os projetos quanto a indicação dos professores orientadores, formalizando, assim, a institucionalidade de todo o processo. $\mathrm{O}$ procedimento visa garantir que todo aluno tenha amparo institucional para desenvolver seu trabalho de conclusão, com amplo acesso á infraestrutura de ensino, pesquisa e extensão do instituto.

\section{Desenvolvimento do trabalho e defesa da monografia}

O segundo estágio do projeto é realizado por meio da disciplina de Projeto Temático em Geologia II, oferecida na nona etapa e coordenada por dois professores. Nessa disciplina, á abordada de forma mais detalhada a diferença entre a metodologia lógica e epistemológica de um problema científico e as técnicas e metodologias analíticas que são utilizadas para testar as hipóteses levantadas. Além disso, objetiva-se que o aluno possa entender em profundidade os protocolos de cada técnica analítica a ser utilizada, de modo a reconhecer os limites de seus usos e o grau de precisão e resolução que as mesmas apresentam. Por fim, a compreensão sobre a organização do trabalho em todas suas etapas deve ser apresentada em termos de um completo fluxograma projetual (work flow), o qual deve dispor também o cronograma e os pontos críticos de cada momento importante de desenvolvimento do projeto. A disciplina também organiza e encaminha todas as solicitações de uso dos laboratórios e das atividades de campo. Essas demandas, devidamente orientadas por atos normativos aprovados pelo Conselho da Unidade, são encaminhadas à secretaria do Instituto e para os respectivos laboratórios que foram demandados. Ao final da disciplina, cada aluno apresenta o problema, hipóteses e técnicas que utilizará em seu trabalho, detalhando cada uma delas, bem como o estado da arte do projeto que deve claramente indicar que mais de $70 \%$ dos dados já foram obtidos.

No último estágio desenvolvido pela disciplina de Projeto Temático em Geologia III, também coordenada por dois professores, incentiva-se a integração de dados, elaboração de modelos geológicos e a redação final da monografia. Depois de uma apresentação do trabalho no âmbito de um seminário da disciplina, a monografia é submetida a uma banca de avaliação composta por dois membros. A banca de avaliação técnica e específica pode recomendar o trabalho, caso tenha alto nível técnico, para a banca de louvor acadêmico. O Fórum de Disciplinas dos Projetos Temáticos e a Comissão de Graduação ordenam os trabalhos indicados de acordo com as maiores notas e submetem os cinco primeiros à Banca de Louvor Acadêmico, composta por cinco membros, dos quais três são externos à Universidade. $\mathrm{O}$ ato de avaliação pela Banca de Louvor é público e pretende dar visibilidade a todos os agentes do processo, em especial aos professores orientadores das monografias e à própria instituição.

\section{Sinopse quantitativa dos conteúdos e projetos apresentados}

Desde a primeira edição dos projetos temáticos em 2001 até a $13^{\text {a }}$ realizada em 2013, foram aprovados 330 projetos temáticos, em uma média de 25,3 projetos por ano. Apresentamos na Tabela 2 uma sinopse quantitativa de cada Itinerário Formativo. Dos sete itinerários formativos, quatro se destacam como aqueles que acolheram o maior número de trabalhos, a saber: a) Geotectônica, petrologia, geoquímica, geologia regional; b) Estratigrafia, geologia sedimentar, paleontologia e geologia do petróleo; c) Geologia ambiental, geologia urbana, geotecnia e hidrogeologia; e d) 
Recursos minerais e carvão. Diferentemente do que se esperaria, o itinerário de Geologia ambiental, que não faz parte da atuação profissional clássica, ocupa a terceira posição, consolidando essa área como importante na formação atual e futura de geólogos. Isso demonstra como os projetos temáticos ajudaram a desenvolver modalidades de atuação profissional que há uma década não recebiam a atenção e o esforço institucional para seu desenvolvimento, mas que, do ponto de vista da formação e do mercado de trabalho, passaram a ser tão importantes quanto as áreas tradicionais do curso.

$\mathrm{Na}$ Tabela 2, visualizam-se também os subtemas dos quatro itinerários formativos com maior concentração de trabalhos. Destacam-se pelo número de trabalhos aqueles subtemas relativos à petrologia, geologia do petróleo, análise de fácies e modelos deposicionais, hidrogeologia, e recursos minerais não metálicos e metálicos. Além disso, a tabela evidencia que já começam a fazer-se presentes subtemas que apontam as mais recentes perspectivas profissionais, como aqueles relacionados à geoconservação, patrimônio geológico, e geoturismo.
Reflexões finais: democracia, diversidade de ideais e qualidade da formação profissional

A mudança de paradigma da formação profissional no curso de geologia deu-se por meio de um longo processo que ocupou praticamente toda a década de 1990. Esse processo teve lugar bem depois das discussões e resoluções do primeiro Seminário Nacional de Ensino de Geologia, ocorrido uma década antes, em 1982. Isso demonstra a dificuldade das instituições de ensino de implementar mudanças curriculares naquela época, mesmo considerando-se que a crise do mercado profissional clássico da geologia havida na década de 1980 exigia respostas urgentes na reformulação do processo formativo. Parte da letargia pode ser atribuída ao mito de formação de um "geólogo voluntarista, mapeador e amostrador", que foi própria da fase heroica dos anos de 1960 e parte de 1970, mas a maior parte das dificuldades residia na herança autoritária imposta às instituições de ensino durante o período da ditadura militar que vigorou até a metade da década de 1980. Nesse período, não havia sequer processos democráticos de eleição dos

Tabela 2. Quantidade de trabalhos apresentados em cada itinerário formativo (IF) e seus subtemas

\begin{tabular}{|c|c|c|c|}
\hline $\begin{array}{l}\text { ITINERÁRIO FORMATIVO } \\
\text { (IF) }\end{array}$ & SUBTEMA & $\begin{array}{c}\% \mathrm{~s} / \\
\mathrm{IF}\end{array}$ & $\% \mathrm{~s} / \mathrm{T}$ \\
\hline \multirow{5}{*}{$\begin{array}{c}\text { GEOTECTÔNICA, } \\
\text { PETROLOGIA, } \\
\text { GEOQUÍMICA, } \\
\text { GEOLOGIA REGIONAL }\end{array}$} & Petrologia & 47 & \multirow{5}{*}{28} \\
\hline & Geocronologia, geoquímica isotópica, traços de fissão & 19 & \\
\hline & Tectônica, geologia estrutural & 18 & \\
\hline & Petrologia e estratigrafia de rochas vulcânicas & 12 & \\
\hline & Geofísica & 4 & \\
\hline \multirow{4}{*}{$\begin{array}{l}\text { ESTRATIGRAFIA, } \\
\text { GEOL. SEDIMENTAR, } \\
\text { PALEONTOLOGIA E } \\
\text { GEOL. PETRÓLEO }\end{array}$} & Petróleo - PRH12 & 53 & \multirow{4}{*}{23} \\
\hline & Análise de fácies, modelos e sequências deposicionais & 26 & \\
\hline & Paleontologia, bioestratigrafia & 16 & \\
\hline & Sedimentologia & 5 & \\
\hline \multirow{5}{*}{$\begin{array}{l}\text { GEOL. AMBIENTAL, } \\
\text { GEOL. URBANA, } \\
\text { GEOTECNIA E } \\
\text { HIDROGEOLOGIA }\end{array}$} & Hidrogeologia & 35 & \multirow{5}{*}{21} \\
\hline & Geoquímica ambiental & 23 & \\
\hline & Gestão, avaliação, impactos ambientais & 18 & \\
\hline & Geotécnica, áreas de risco, solos, geologia urbana & 15 & \\
\hline & Geoconservação, patrimônio geológico, geoturismo & 3 & \\
\hline \multirow{5}{*}{$\begin{array}{c}\text { RECURSOS MINERAIS E } \\
\text { CARVÃO }\end{array}$} & Não metálicos & 35 & \multirow{5}{*}{18} \\
\hline & Metálicos & 31 & \\
\hline & Geoquímica orgânica, carvão & 19 & \\
\hline & Argilas & 11 & \\
\hline & Hidrotermalismo e recursos minerais & 4 & \\
\hline \multicolumn{3}{|c|}{ GEOLOGIA MARINHA E COSTEIRA } & 5 \\
\hline \multicolumn{3}{|c|}{ GEOPROCESSAMENTO E SENSORIAMENTO REMOTO } & 3 \\
\hline \multicolumn{3}{|c|}{ MINERALOGIA E TECNOLOGIA MINERAL } & 2 \\
\hline \multicolumn{3}{|c|}{ TOTAL (T) } & 100 \\
\hline
\end{tabular}


mandatários das instituições e tampouco procedimentos de renovação curricular que considerassem amplas discussões junto à comunidade universitária e profissional. Pior que isso, qualquer crítica ao processo de ensino aprendizagem era vista como afronta ao regime. A mudança curricular ficou, assim, dependente também da mudança da cultura autoritária dentro das próprias universidades.

A mudança curricular e a introdução dos Projetos Temáticos em Geologia como método de realizar o trabalho de conclusão aprofundou a busca por democracia no processo de ensino e aprendizagem para além da eleição dos mandatários da instituição. Por meio dos projetos, todos os professores podem contribuir com a formação final dos alunos, e não apenas a "comissão de campo", na maior parte das vezes liderada por poucos professores, que acabavam por priorizar suas próprias 'áreas de interesse'. No período houve democratização do acesso dos alunos de graduação a todos os laboratórios e estrutura técnica-científica da instituição. Além disso, ampliaram-se os temas considerados como importantes na formação do geólogo, trazendo para dentro da estrutura curricular novas áreas, procedimentos, técnicas e problemas colocados na sociedade. Como nunca, a formação de geólogos passou a considerar a existência de uma sociedade que também demandava a contribuição de profissionais em geologia em diversas problemáticas, para além de uma formação voltada exclusivamente para as grandes empresas do setor. Isso fez aumentar as parcerias e relações com a sociedade.

Os projetos temáticos levam o futuro profissional a imergir na complexidade da produção técnico-científica de alto nível. Isso porque, além do acesso à estrutura laboratorial ou da própria profundidade científica e epistemológica do problema tratado, os projetos são assistidos por nada menos que 10 professores doutores. Destes, dois professores são orientadores, seis professores ministram as três disciplinas de projetos temáticos e, por fim, dois professores avaliam a monografia final em uma banca de avaliação. Além disso, o próprio aluno acompanha toda a tramitação institucional do projeto, desde a homologação na Comissão de Graduação, o encaminhamento institucional das demandas laboratoriais e atividades de campo. $\mathrm{Ou}$ seja, o aluno também deve reconhecer o terreno institucional que viabiliza o projeto e incluir os problemas que por ventura ocorram em seu processo projetual. No final, o aluno acaba obtendo uma primeira medida profissional do tempo, esfor- ço, procedimentos, processos, materiais, custos necessários para resolver um problema técnico-científico em geologia. Com isso, espera-se que o futuro profissional esteja mais apto a empreender e resolver problemas.

Além da diversificação de áreas temáticas e técnicas, também ampliaram-se os locais dos trabalhos de campo, que passaram a incluir outros estados brasileiros que não apenas o Rio Grande do Sul, e vários países da América do Sul, África e Antártida. Às novas problemáticas técnicas, adicionaram-se novas questões logísticas e estruturais dos trabalhos de campo, além do intercâmbio cultural que tais expedições propiciam. Isso ajuda a desenvolver processos de formação de geólogos não apenas aprisionados em algumas técnicas aprendidas na origem, mas capazes de lidar com problemas geológicos do país, do continente e do mundo.

O conjunto de medidas propiciou que os estudantes pudessem trabalhar com temas e problemas muito avançados já em sua graduação, como petrologia mantélica experimental, tecnologias geossociais, ontologia da informação geológica, estratigrafia de rochas vulcânicas, modelização de jazidas, entre outros. Isso demonstra que embora haja um nível mínimo que os trabalhos devam ter, não há limites para o nível intelectual e técnico que podem vir a alcançar, propiciando um ambiente de ensino-aprendizagem que favorece a inovação e a interdisciplinaridade. Como indicador de um processo que qualifica sobremaneira o ensino de graduação, tem-se a publicação de diversos projetos temáticos em revistas especializadas nacionais e internacionais. O fato também serve como indicador do grau de autonomia que o estudante alcançou para pensar por si mesmo.

Em diversos encontros e reuniões de avaliação da comunidade envolvida, tem sido colocado que o grande fator responsável sobre a qualidade dos trabalhos seria devido ao empenho dos orientadores dos projetos temáticos. Certamente a orientação dos trabalhos é um aspecto fundamental para que os alunos possam avançar. Porém, o foco da equipe de professores do Fórum das Disciplinas de Projetos Temáticos tem insistido no fato de que a excelência é resultado de um conjunto de fatores que a instituição deve propiciar, incentivar e garantir. Podemos eventualmente ter trabalhos muito bons resultantes do empenho heroico e voluntarioso de estudantes e orientadores, mas a formação profissional de alto nível não pode depender apenas de atos voluntariosos dos indivíduos. Antes de tudo, 
ela deve estar presente nas estratégias e diretrizes da instituição. Claro que a discussão entre professores orientadores versus Fórum das Disciplinas de Projetos Temáticos (instituição, estrutura curricular etc.) ocorre dentro de um ambiente universitário cada vez mais competitivo, no qual os indivíduos precisam estar sempre em evidência. Por outro lado, é importante que os educadores de nível superior tenham claro que todos os trabalhos de conclusão dos alunos devem ter sua qualidade garantida pelo esforço institucional, e não apenas deste ou daquele indivíduo que, do ponto de vista competitivo, parece ser o que deveria prevalecer. Deve-se forçosamente reconhecer que mesmo os projetos que por ventura um e outro pesquisador tenham conquistado por seus méritos individuais, não seriam possíveis e talvez sequer seriam destinados aos indivíduos se não fosse a instituição que os abriga. Dessa maneira, os projetos temáticos ajudam a comunidade a balancear suas tensões entre capacidade e esforço do pesquisador versus qualidade e condições institucionais. Nunca se deve esquecer que as sociedades de conhecimento de alta performance são matriciais, isto é, há uma complexa interrelação dos elementos, a exemplo de um ecossistema. O domínio excessivo de algumas espécies pode levar ao arrasamento da comunidade e, mesmo, do ecossistema.

Ademais, o florescimento de vários padrões científicos e técnicas contribuem para a ideia de que o melhor modo para a produção científica e técnica, capaz de favorecer a inovação, é o debate de ideias em um ambiente democrático. Dessa maneira a instituição e sua comunidade renovam suas capacidades e potencialidades em um ambiente no qual não há limite para crescer e inovar.

\section{Referências Bibliográficas}

Assine M.L. 1994. Repensando os cursos de graduação em Geologia. Cadernos IG-Unicamp, 4(1):34-65.

Janasi, V.A., 2012. O Ensino de Graduação em Geociências no Brasil: Avaliação e Perspectivas (por solicitação da SBG, SBGf, SBGq). São Paulo: IGc-USP. (Apres. Powerpoint).

Keane, C. 2010. Geoscience enrollments and degrees continue their sharp rise in 2009-2010. American Geological Institute, Geoscience Currents n.31 (27 april 2010).

Menegat R., Araújo A.M. de. 2005. Irajá Damiani: a invenção da geologia no sul do Brasil. Episteme, 17:06-24.

Pinto I.D. 2007. Curso de Geologia. Porto Alegre: Inst. Geoc. UFRGS. 182p.

Ramos J.R.A. 1987. Cursos de geologia completam 30 anos (CAGE: 1957). Rio de Janeiro, Anu. Inst. Geocienc., v.11.

SBG. Sociedade Brasileira de Geologia. 1983. Simpósio Nacional sobre o Ensino de Geologia no Brasil. Currículo Mínimo, 2. 1982, Salvador. Documento Final... São Paulo: SBG. 73p.

SBG. Sociedade Brasileira de Geologia. 1984. A formação do geólogo nas universidades brasileiras: um retrato de duas décadas. São Paulo: SBG.

USGS. U.S. Geological Survey. 2011. Geology for a changing world 2010-2020: implementing the U.S. Geological Survey science strategy: U.S. Geological Survey Circular 1369, 68 p. 